CENTRE for ECONOMIC

$P$ E R F O R M A N C E

CEP Discussion Paper No 791

May 2007

\title{
Entry and Asymmetric Lobbying: Why Governments Pick Losers
}

Richard E. Baldwin and Frédéric Robert-Nicoud 


\begin{abstract}
Governments frequently intervene to support domestic industries, but a surprising amount of this support goes to ailing sectors. We explain this with a lobbying model that allows for entry and sunk costs. Specifically, policy is influenced by pressure groups that incur lobbying expenses to create rents. In expanding industries, entry tends to erode such rents, but in declining industries, sunk costs rule out entry as long as the rents are not too high. This asymmetric appropriability of rents means losers lobby harder. Thus it is not that government policy picks losers, it is that losers pick government policy.
\end{abstract}

JEL Classifications: H32, P16

Keywords: Lobbying, Sunset Industries, Sunk Costs

This paper was produced as part of the Centre's Globalisation Programme. The Centre for Economic Performance is financed by the Economic and Social Research Council.

\title{
Acknowledgements
}

We are grateful to Paola Conconi, Gene Grossman, Douglas Irwin, Alan Manning, Marc Melitz, Doug Nelson, Ricardo Puglisi, Jaume Ventura, Thierry Verdier, two anonymous referees, and editor Roberto Perotti as well as to seminar participants at Cergy-Paris, Geneva, LSE, Nottingham, Paris School of Economics, Princeton, Stockholm, University College Dublin, University of Wisconsin, Zurich, the conference on Lobbying and Institutional Structure of Policy Making (La Sapienza, Rome), the CEPR workshop on Trade, Industrialisation and Development (ECARES, Brussels), the NBER ITI Spring Meeting (Boston), and the Research in International Economics and Finance conference (CERAS, Paris) for comments and suggestions. We gratefully acknowledge financial help from the Swiss National Fund (Grant no. 100012-103992/1).

Richard E. Baldwin is Professor of International Economics at the Graduate Institute of International Studies, Avenue de la Paix 11A, 1202 Geneva, Switzerland. Frédéric Robert-Nicoud is an Associate of the Globalisation Programme at the Centre for Economic Performance and Lecturer in Economic Geography, London School of Economics.

Published by

Centre for Economic Performance

London School of Economics and Political Science

Houghton Street

London WC2A $2 \mathrm{AE}$

All rights reserved. No part of this publication may be reproduced, stored in a retrieval system or transmitted in any form or by any means without the prior permission in writing of the publisher nor be issued to the public or circulated in any form other than that in which it is published.

Requests for permission to reproduce any article or part of the Working Paper should be sent to the editor at the above address.

(C) R. E. Baldwin and F. Robert-Nicoud, submitted 2007

ISBN 9780853281672 


\section{Introduction}

Governments that try to pick winners and losers usually choose the latter, according to an old adage. Some of the clearest examples of this stylized fact come from trade policy. In the United States and Europe, the most protected sectors (agriculture, textiles, clothing, footwear, steel, and shipbuilding) have all been in decline for decades. Counterexamples are rare. Even when a growing sector gets protection, as did the U.S. semiconductor industry, the protection tends to be focused on market segments-like memory chips-in which the domestic industry is losing ground. A related phenomenon is the "NIMBY" syndrome (Not in My Back Yard), whereby special interest groups seem to fight harder to avoid losses than they do to achieve gains.

In seeking to account for this phenomenon, the natural place to start is with the political economy literature. The key approach for our purposes is the "pressure group" or lobbying approach that was launched by the classic papers of Stigler (1971) and Peltzman (1976) in the context of industrial regulation. This approach subsequently found a natural home in the field of international trade after a series of papers showed that it provided important insights on why observed trade policy deviates so radically from welfaremaximizing policies. The path-breaking papers here are Hillman (1982), which took the political-support function approach, and Findlay and Wellisz (1982), which introduced the tariff-formation function approach. More recently, the pressure-group approach has been extended to include more explicit modeling of how lobbying expenditures affect policymakers' choices. Magee et al. (1989) work with a model where political contributions influence the outcome of elections, but the dominant model in this literature is now the "protection for sale" model of Grossman and Helpman (1994). As Rodrik (1995) notes, the great advantage of this model is that it provides clear-cut micro foundations for lobbying and its effects in a tractable and fairly general setting. ${ }^{1}$

\subsection{The losers' paradox}

At the heart of the pressure-group approach is the presumption that special interest groups (SIGs) who spend the most on lobbying or other political activities are, other things equal, the ones that get the most government support. Given this view, the success of sunset industries in winning a disproportionate share of government support is paradoxical. After all, politicians should value the lobbying dollars of expanding industries as much as those of declining industries. Moreover, an industry's ability to finance lobbying expenditures and its interest in obtaining government support should be positively related to its size, employment, and/or profitability; one would expect the highest levels of government support in the biggest and strongest sectors rather than in ailing sectors. In the same light, the NIMBY syndromeobserved in issues ranging from the health-care reform to the location of landfill sites-is curious because lobbying to reverse losses and lobbying to secure new gains would seem to be equally attractive to special interest groups.

Our paper uses the pressure-group approach-in particular, that of Grossman and Helpman (1994)-to account for the surprising amount of support that goes to declining industries. Our basic story is simple. Government policy is influenced by pressure groups whose lobbying is expensive. Special interest groups spend money in order to create rents

\footnotetext{
${ }^{1}$ See Dixit et al. (1997) for a synthesis of the "Protection For Sale" approach and Baldwin (1987) for a generalization.
} 
that they can appropriate. ${ }^{2}$ There is, however, a strong asymmetry in the ability of expanding and contracting industries to appropriate the benefits of lobbying. In an expanding industry, policy-created rents attract new entry that erodes the rents. In the extreme, free and instantaneous entry obviates all rents. This is not true in declining industries. Since sunk market-entry costs (e.g., unrecoverable investments in product development, training, and brand name advertising) create quasi-rents, profits in declining industries can be raised without attracting entry as long as the level of quasi-rents does not rise above a normal rate of return on the sunk capital. Plainly, an asymmetry in the appropriability of rents implies an asymmetric incentive to lobby. The result is that losers lobby harder, so it is not government policy that picks losers but rather the losers who pick government policies. A corollary to this reasoning accounts for the observed tendency of special interest groups to fight harder to avoid losses than they do to win gains.

\subsection{Review of the literature}

Many explanations of the loser's paradox have been suggested. One of the earliest and bestknown expositions regards the conservative social welfare function (CSWF) of Corden (1974). As Corden introduces it, "any significant absolute reduction in real incomes of any significant section of the community should be avoided. ... In terms of welfare weights, increases in incomes are given relatively low weights and decreases very high weights." Although this sort of government-with-a-heart description may have a good deal of explanatory power, it comes close to assuming the answer. Moreover, at least in developed nations, governments have a great many policies for redistributing income and cushioning shocks (income taxes, unemployment insurance, retraining schemes, etc.) and so, even if "caring" were a major motive in government policy, an optimizing government would separate industry support from pure income distribution considerations. An even more important critique is that the conservative social welfare function does not explain why some declining industries do not win massive government support. In the 1980s, for instance, the real wages of U.S. unskilled workers fell substantially but only a small subset of these attracted government support. As the work of Goldberg and Maggi (1999) shows, it was the well-organized sectors (e.g., U.S. apparel workers) that induced the US government to adopt distortionary policies that softened the fall in their real incomes. In the same spirit as the CSWF approach are the equity-concern model of Baldwin (1982) and the status-quo model of Lavergne (1983).

One of the most intuitive explanations for the loser's paradox turns on Anne Krueger's use of the "identity bias" to account for what she calls "asymmetries in the political market." The bias, according to Krueger (1990), reflects the fact that people care more about the welfare of known specific individuals than that of unidentified faceless individuals. To see how such a bias could explain asymmetric government support, the author contrasts the impact of a subsidy to a declining sector with one to an expanding industry. Both subsidies will alter the allocation of employment, but in the ailing industry the jobs "saved" are identified ex ante with specific individuals whereas the jobs created in the expanding sector cannot be identified with any specific individual, ex ante. In a way, this model provides psycho-micro foundations, of the type associated with Schelling (1984), for the CSWF approach. As such, Krueger's explanation relies on the shape of the policymakers' objective function and thus shares the shortcomings of the CSWF solution. Likewise,

\footnotetext{
${ }^{2}$ Using U.S. data, Gawande and Bandyopadhyay (2000) provide some evidence that protection is indeed 'for sale'. See note 5 .
} 
Rotemberg (2003) proposes a theory in which a small degree of voter altruism in direct and representative democracies alike yields protection to import-competing sectors in which the level of income of the sector-specific factor is low.

A related paper that relies on more standard microeconomic behavior is Fernandez and Rodrik (1991). These authors use a mechanism that is related to the notion of identity bias in order to account for the reluctance of governments to adopt changes in policies (i.e., reforms). To see this, consider a simple economy with $45 \%$ of workers in one sector, $55 \%$ in another, and a hypothetical reform that will help workers in the initially small sector and hurt those in the initially big sector. Moreover, the reform will shift employment so that $60 \%$ of workers are eventually in the sector that is helped - that is, the sector that was initially small. If each worker knew what her fate would be ex ante, then the reform would easily garner support from a majority of workers. However, workers in the initially larger sector do not know ex ante in which sector they will end up ex post; the probability that they move to the helped sector is quite small, just 15/55, so each one of them may oppose the reform ex ante. Observe that, although the identity bias operates via the psychology of policymakers in the Krueger model, the Fernandez-Rodrik model relies on nothing more than individual rationality and the assumption of a random selection device.

Another solution to this puzzle that displays solid microfoundations is proposed by Hillman (1989), who views the use of trade policy as a "social insurance" against exogenous changes in comparative advantage; this model could account for the asymmetric protection of losers. Although it is difficult to discern the underlying forces in their model, Magee et al. (1989) also claim to explain asymmetric protection with their "compensation effect."

Sauré (2005) argues that subsidies to importing industries represent a crucial piece in trade agreements. If free trade leads to complete specialization then each country has an incentive to set tariffs that improve its own terms of trade, making the free-trade agreement not enforceable. Subsidies reduce the incentive to engage in a trade war: by subsidizing their own comparative-disadvantaged industries, countries limit one another's abilities to manipulate world prices in their favor. In contrast, we emphasize the role of lobbying and the role of asymmetric shocks at the sectoral level (e.g., a surge in imports rather than the level of imports per se) in explaining asymmetric protection.

Another line of research that is tangentially related to the losers' paradox is the study of the collapse of senescent industry. The seminal papers, Hillman (1982) and Cassing and Hillman (1986), apply the political-support function approach to understand why declining industries continue to decline despite the protection they receive, putting a special emphasis on their eventual collapse. Subsequent important contributions include Matsuyama (1987), Van Long and Vousden (1991), and Brainard and Verdier (1997). Although this branch of the literature is also concerned with sunset sectors, its focus is quite different in that it takes as a starting point the fact that declining industries will receive protection; our paper seeks to understand why this is so. ${ }^{3}$

The main idea in our model is based on an unpublished manuscript by one of the authors, Baldwin (1993), but our paper differs significantly in its modeling strategy and in the rigor of its analysis. Baldwin (1993) relied on unanticipated but permanent changes in the degree of foreign competition to generate differences between winners and losers, not

\footnotetext{
${ }^{3}$ Many of these papers also continue to conjecture why declining rather than expanding industries so frequently garner government support, but this is not their main focus. In particular, Brainard and Verdier (1997) suppose that credit constraints prevent an expanding sector from investing in the lobbying it needs to get protection. Also, Hillman (1989) discusses the asymmetrical effects of entry, but they are not incorporated into his formal model.
} 
explicitly allowing for the simultaneous existences of both types. ${ }^{4}$ This paper generalizes Baldwin (1993) by using a model in which different industries face idiosyncratic temporary demand shocks, agents are forward looking, and policy setting is intertemporal. We also note that Grossman and Helpman (1996) extended the basic asymmetric lobbying framework of Baldwin (1993) by considering the free riding of new entrants in "winning" sectors. Their main argument is that it is free riding rather than entry that causes the asymmetry; we shall revisit this issue.

It is worth stressing that our proposed solution based on sunk-cost is complementary to all the aforementioned solutions.

\subsection{Empirical studies of the losers' paradox}

The lobbying success of losers-the losers' paradox-has been extensively documented empirically. In the United States, Hufbauer and Rosen (1986), Hufbauer et al. (1986), and Ray (1991) have documented that declining industries receive a disproportionate share of protection. Particularly favored industries are agriculture, textiles, footwear, clothing, and steel, all of which have experienced secular declines in employment and GDP shares in the United States. In their introduction, Hufbauer and Rosen (1986) write:

With bipartisan regularity, American presidents since Franklin D. Roosevelt have proclaimed the virtues of free trade. They have inaugurated bold international programs to reduce tariff and non-tariff barriers. But almost in the same breath, most presidents have advocated or accepted special measure to protect problem industries. ... The United States is not the only country to have experienced competition in mature industry from foreign goods. Most industrial countries, in Europe, Japan and elsewhere, have encountered similar difficulties.

More directly related to our issue, many econometric studies have found that being a "loser" in terms of employment, output, or import competition actually helps an industry get more protection. Baldwin (1985) and Baldwin and Steagall (1994) find a strong correlation between positive "serious injury" findings of the U.S. International Trade Commission and reduced industry profits and employment. Glismann and Weiss (1980) find that above-trend income increases are correlated with reduced protection in Germany between 1880 and 1978. Marvel and Ray (1983) find that an industry's growth rate has a negative impact on its level of protection. This is confirmed by Baldwin's (1985) finding that the industries most successful at resisting tariff cuts in the Tokyo Round were characterized by, inter alia, relatively slow or negative employment growth as well as by high and rising import penetration ratios. More recently, econometric evidence from Ray (1991) shows that declining industries tend to get more protection and Trefler (1993) finds that an increase in import penetration tends to increase the level of protection a sector is afforded. ${ }^{5}$ Furthermore, a number of econometric studies have found that average tariff levels tend to rise in recessions (see e.g. Ray 1987; Hansen 1990; O’Halloran 1994). Gallarotti (1985) finds

\footnotetext{
${ }^{4}$ The novel mechanism we are proposing in this paper combines negative shocks and the importance of sunk entry costs within a given industry. Marceau and Smart (2003) propose a theory in which sectors that rely heavily on sunk costs are more successful in obtaining tax breaks.

${ }^{5}$ Interestingly, Gawande and Bandyopadhyay (2000), who explicitly test the Grossman-Helpman framework using cross-industry data on the coverage ratio of U.S. non-tariff barriers coverage ratios and US lobbying spending, find a negative relationship between import penetration and the level of protection when the sector is not organised; this relationship is positive otherwise.
} 
similar results concerning U.S. tariffs in the 19th and 20th centuries. In a similar light, the time-series approach of Bohara and Kaempfer (1991) shows that tariffs are Granger-caused (positively) by unemployment and real GNP. In ongoing work on U.S. data, Baldwin et al. (2006) regress lobbying expenditure on the interaction between negative demand shocks and measures of "sunk-ness" of capital (in addition to a group of controls) and some specifications report a positive coefficient in line with theory. Interestingly, the coefficient of demand shocks alone is not significant in a statistical sense; it is only when interacted with a measure of sunk-ness that demand shocks become significant.

We also note that the systematic favoring of losers is actually inscribed in international and national trade laws. The General Agreement on Tariffs and Trade (GATT) generally prohibits countries from pursuing policies that favor domestic firms over foreign firms. The major exceptions to this principle (safeguards, dumping duties, and countervailing duties) involve situations where imports cause or threaten to cause material injury to an established industry. In contrast, there are no general exceptions that allow a country to promote the interests of an expanding industry. These principles can also be found in national laws. For example, U.S. trade laws make "decline" (appropriately interpreted) an explicit requirement for trade protection.

If one accepts the view that political economy forces shape national and international trade laws, then the foregoing asymmetry is puzzling. Lobbying dollars of expanding industries should be just as welcomed by politicians as the dollars of declining industries. It is therefore odd that politicians should have adopted laws that greatly restrict their ability to promote profits in expanding sectors even as they create loopholes that boost the profits of declining industries.

\subsection{Plan of the paper}

The paper is structured as follows. Section 2 develops the static economic and politicaleconomic model. Section 3 introduces the dynamic structure of the model and solves the game allowing for entry. Section 4 considers two extensions, and Section 5 summarizes the results of the paper and discusses some of the policy implications of our analysis.

\section{The basic model}

Formalization of the asymmetric lobbying effects discussed in the Introduction requires a model that first shows how industry support affects the fortunes of firms that may lobby and then connects these changing fortunes to the political decision-making process. Toward this end we present a simple model whose special features simplify the algebra; we shall argue, however, that the basic results in the paper do not qualitatively depend upon these special features. In particular, we combine a standard monopolistic competition model (which can be thought of as the closed economy version of a "new" trade model à la Flam and Helpman 1987) with the lobbying model of Grossman and Helpman (1994). ${ }^{6}$

\footnotetext{
${ }^{6}$ Typically, the new political economy literature works with a Ricardo-Viner model. In our model, since capital investments are sunk, it follows that capital is sector specific, like in the Ricardo-Viner framework. In contrast to that framework, however, neither the returns to the factor that is mobile across sectors (labor) nor the returns to the factors specific to other sectors are affected by the shocks or by the protection granted to a sector in particular. This is a consequence of the quasi-general equilibrium nature of our model which features quasilinear preferences and a constant-return-to-scale numéraire sector that uses labor only.
} 


\subsection{Tastes and technology}

Consider an economy with $M+1$ sectors. The "plus one" sector uses labor $L$ to produce a homogenous good $A$ under constant returns and perfect competition. By choice of units, one unit of $L$ produces one unit of $A$. There is also a large number $M$ of symmetric industrial sectors that are characterized by increasing returns and monopolistic competition. A typical firm faces variable costs equal to $\beta w x$, where $x$ is the firm output, $\beta$ is the unit labor requirement, and $w$ is the wage. In this section, to fix ideas we take the number of firms as given, delaying considerations of entry to Section 3 . When entry is allowed, we assume that a new manufacturing firm needs to sink one unit of capital in order to operate, with this capital produced by using $L$ only.

Instantaneous utility is linear in the consumption of $A$ and a two-tier index of industrial goods consumption:

$$
U=A+\sum_{m=1}^{M} \alpha_{m} \ln D_{m}, D_{m} \equiv\left(N_{m}^{-\chi / \sigma} \int_{j=0}^{N_{m}} c_{m j}^{1-1 / \sigma} \mathrm{d} j\right)^{1 /(1-1 / \sigma)}
$$

and $\sigma>1$. Here $D_{m}$ is the CES (constant elasticity of substitution) consumption index for a typical industrial sector $m, c_{m j}$ is the consumption of variety $j$ in sector $m, N_{m}$ is the number (mass) of such symmetric varieties within a typical sector, $\sigma$ is the constant elasticity of substitution among varieties, and $\alpha_{m}$ is a demand shift parameter. The number of differentiated product sectors $M$ is fixed.

Note that the inclusion of the parameter $\chi$ makes the CES aggregate $D_{m}$ more general than the usual functional form. The parameter $\chi$ measures the preference for diversity. In the standard love-for-variety preferences, $\chi$ is taken to be zero, implying that consumers could become unboundedly happy by consuming an infinitely small amount of infinitely many varieties. To avoid this feature and to simplify our algebraic expressions, we neutralize the love-of-variety aspect by taking $\chi=1$.

Importantly, we assume random preferences in the following sense: $\alpha_{m}$ is either $\alpha_{H}$ or $\alpha_{L}$, where $\alpha_{H}>\alpha_{L}$; that is, each sector faces either high or low demand. ${ }^{7}$

The model features a continuum of consumers endowed with a share-equal to $s(i)$ for consumer $i-$ of the economy's labor and of all firms' equities, so that the individual budget constraint is

$$
s(i)\left(w L+\sum_{m=1}^{M} \Pi_{m}-T\right)=p_{A} A_{i}+\sum_{m=1}^{M} \int_{j=0}^{N_{m}} \tau_{m} p_{m j} c_{m j} \mathrm{~d} j,
$$

where $\Pi_{m}$ is the total operating profit from all sector- $m$ firms, $L$ is the economy wide labor endowment, $T$ is the total lump-sum tax collected, and $\tau$ is an ad valorem tax or subsidy factor (i.e., the rate is $\tau-1$, which is a tax if positive or a subsidy if negative). Producer prices are denoted as $p$, so consumer prices are $\tau p$ ( $\tau$ is fully passed on to consumers under DixitStiglitz monopolistic competition).

We normalize the economy's total labor endowment to unity. ${ }^{8}$ Hence the optimal aggregate demand for a typical variety $j$ in a typical sector $m$ and the aggregate demand for $A$ and are respectively given by

\footnotetext{
${ }^{7}$ Our qualitative results would hold if we assumed technology shocks rather than demand shock (more on this in Section 4.2).

${ }^{8}$ Accordingly, we assume that $\Sigma_{m} \alpha_{m}$ is small enough that production of $A$ is always positive at equilibrium.
} 


\section{(3)}

$$
c_{m j}=\frac{\alpha_{m}\left(\tau_{m} p_{m j}\right)^{-\sigma}}{\int_{j=0}^{N_{m}}\left(\tau_{m} p_{m j}\right)^{1-\sigma} \mathrm{d} j}, A=\frac{w+\sum_{m=1}^{M} \Pi_{m}-T-\sum_{m=1}^{M} \int_{j=0}^{N_{m}} \tau_{m} p_{m j} c_{m j} \mathrm{~d} j}{p_{A}} .
$$

As usual, the producer price $p_{m j}$ of a typical industrial firm $j$ is related to marginal costs according to the expression $p_{m j}(1-1 / \sigma)=\beta w$. By choice of units (viz. $\beta=1-1 / \sigma$ ) and taking $L$ as numéraire, we can without loss of generality set $p_{m j}=1$ for all firms in all $M$ sectors. Consequently, a typical firm's flow of operating profit is given by ${ }^{9}$

$$
\pi_{m}=\frac{\alpha_{m}}{\sigma \tau_{m} N_{m}}, \alpha_{m} \in\left\{\alpha_{L}, \alpha_{H}\right\}
$$

and $\Pi_{m} \equiv N_{m} \pi_{m}$ is total operating profit in sector $m$ (within-sector symmetry allows us to drop the firm subscript). Using the ex ante symmetry of sectors, it proves convenient to index sectors by the state of demand faced, denoting the $\Pi$ earned by those facing high and low demand as $\Pi_{H}$ and $\Pi_{L}$, respectively; clearly $\Pi_{H}>\Pi_{L}$ for any given level of $\tau_{m}$.

\subsection{Utilitarian benchmark}

In the sequel we shall introduce a political process governing the choice of $\tau$, but intuition is served by first identifying the socially optimal $\tau$. Specifically, the government chooses sectorspecific taxes $(\tau>1)$ or subsidies $(\tau<1)$ to maximize aggregate welfare as measured by a scalar $a /(1+a)$ times the sum of consumers' utility. ${ }^{10}$ The $A$-sector is untaxed and the lump-sum tax $T$ is adjusted to maintain a balanced budget. By symmetry of firms, the lump-sum tax revenue (which may be negative) required to implement the vector $\tau$ is just the sum over all $m$ of (1$\left.\tau_{m}\right) N_{m} c_{m}$. Using (4) together with the solutions for $T, p$, and $c_{m}$ in (1), we find that the Benthamite objective is

$$
W \equiv \frac{a}{1+a}\left\{1+\sum_{m=1}^{M} \alpha_{m}\left[\ln \left(\frac{\alpha_{m}}{\tau_{m}}\right)-\frac{1-1 / \sigma}{\tau_{m}}\right]\right\}, \quad a>0
$$

where we have normalized $p_{A}$ to unity by choice of units of $A .^{11}$

Maximizing this with respect to $\tau_{m}$ for all $m$ requires that the government offsets the only distortion in the economy - namely, the monopolistic pricing distortion - and this implies that the optimal utilitarian policy is

$$
\tau_{m}=\beta \equiv 1-\frac{1}{\sigma}
$$

for all $M$ sectors. This result clearly entails a subsidy ( $\tau<1$ is a subsidy whereas $\tau>1$ is a tax) to all industrial sectors because $\sigma>1$. Note also that, since there is only one distortion and since lump-sum taxation is possible, the Benthamite government can attain the first-best

\footnotetext{
${ }^{9}$ The result follows by rearranging the firm's first order condition to $\left(p_{m i}-\beta w\right) c_{m i}=p_{m i} c_{m i} / \sigma$ and then using the demand function and symmetry of varieties.

${ }^{10}$ We introduce $a$ (without loss of generality) in order to facilitate comparison with (8), where $a$ is necessary.

${ }^{11}$ See the Appendix A.1. for details of the calculation.
} 
outcome. With this utilitarian benchmark in hand, we turn to the lobbying game, where the policymaker may be influenced by political contributions.

\subsection{Lobbying}

Hillman (1989) and Baldwin (1985) point out that, under realistic assumptions, elected officials may not be fully aware of the economic interests of their constituents, and their constituents may not be familiar with all the policies (and their economic consequences) championed by their elected representatives. Consequently, as Baldwin (1985) notes, a group of voters "may have to engage in time-consuming and costly lobbying activities to bring its viewpoint to the attention of legislators. Similarly office-seekers need funds to inform the voters of how they have served them or will do so in the future." The so-called pressuregroup model (or lobbying model) developed by Olson (1965) and others focuses on the costs and benefits of lobbying and its impact on policy. This class of models abstracts from electoral politics, assuming that the government is entrenched or at least that every elected government will react in the same way to lobbying.

Explicit consideration of such imperfections would require a model that is much more complicated than the one needed to examine the basic logic of asymmetric lobbying. Thus, following standard practice (see e.g. the political support function approach of Hillman 1989 and the formal lobbying approach of Findlay and Wellisz 1982), we skip the micro modeling of how lobbying funds influence policy choices. Instead, we follow the approach in Grossman and Helpman's seminal 1994 paper in which lobbying expenditures in the form of "contributions" are just assumed to directly enter the objective function of the government.

Specifically, we follow Grossman and Helpman (1994) as simplified in Baldwin and Robert-Nicoud (2006); that is, we model lobbying as a menu auction (Bernheim and Whinston 1986) and we assume that all industrial sectors are perfectly organized in the Grossman-Helpman sense (i.e., all firms in a sector act as one when it comes to political contributions). Contributions made by sector $m$ are denoted as $C_{m}$. Consumers and the untaxed $A$-sector are unorganized and thus do not lobby.

\section{Government's objective, lobbies, and contributions}

As in Grossman and Helpman (1994), the government's objective function $\Omega$ is a weighted sum of lobby contributions and aggregate social welfare $W$ :

$$
\Omega=W+\frac{1}{1+a} \sum_{m=1}^{M} G_{m} I_{m} C_{m} ; G_{m} \in\{0,1\}, I_{m} \in\{0,1\} \forall m,
$$

where the first term $W=a U /(1+a)$ is the utilitarian social welfare function from (5) and where the second term represents total political contributions. The binary variable $G_{m}$ reflects the fact that the government always has the option of rejecting contributions from any sector, and the binary variable $I_{m}$ reflects the lobbying choice of a particular sector $\left(I_{m}=0\right.$ implies no lobbying). ${ }^{12}$ By way of interpretation, note that a pure Benthamite government would be characterized by $a=\infty$ and a pure "Leviathan" by $a=0$, so $a$ captures the extent to which governments care about social welfare as opposed to political contributions. Mitra (1999)

\footnotetext{
${ }^{12}$ In our model, at equilibrium the government will always accept contributions. In a setting where lobbies' interests are correlated and where the elected candidate bargains with the lobbies, Felli and Merlo (2006) show that the elected candidate sets $G_{m}=0$ for some $m$ at equilibrium.
} 
adds a lobby formation stage to the Grossman-Helpman setting. He assumes an exogenous fixed cost of getting organized, which differs across sectors, and studies how this affects the equilibrium outcome. By contrast, we assume that the fixed cost of lobbying is zero for all $\mathrm{m}$, and we endogenize the decision to lobby actively or not. This decision is taken according to an external factor that has nothing to do with an exogenous cost of lobbying per se.

The vectors $\tau$ and $G$ are the government's choice variables. Lobbies contribute in order to induce the government to deviate from the utilitarian first-best outcome. As in the Grossman-Helpman model, we restrict contributions to be globally "truthful". Thus, if an industrial sector $m$ decides to lobby (i.e. $I_{m}=1$ ) then its contribution is $C_{m}(\tau)=\Pi_{m}(\tau)-B_{m}$, where $B_{m}$ is a scalar; if it decides not to contribute (i.e. $\left.I_{m}=0\right)$ then $C_{m}(\tau)=0$ for all $\tau .{ }^{13}$ Here $B$ is the vector of which $B_{m}$ is a typical element.

\section{The all-lobby outcome}

An equilibrium in this world is defined by the government's strategy (i.e., the vectors $\tau$ and $G$ ) and the $M$-sectors' strategies (i.e. the vectors $I$ and $B$ ) that are mutual best responses. The payoff function of a typical sector $m$ is $\Pi_{m}-B_{m}$. The government's payoff function can be written as

$$
\Omega \equiv \frac{a}{1+a}\left\{1+\sum_{m=1}^{M} \alpha_{m}\left[\ln \left(\frac{\alpha_{m}}{\tau_{m}}\right)-\frac{\beta}{\tau_{m}}\right]\right\}+\frac{1}{1+a} \sum_{m=1}^{M} I_{m} G_{m}\left(\frac{\alpha_{m}}{\tau_{m} \sigma}-B_{m}\right),
$$

where we have used equations (4) and (5) and the fact that contributions are truthful.

We shall calculate the $B$-values later. Taking them as given for the moment, we investigate what policy would be chosen if a typical sector chooses to make contributions and the government chooses to accept them (i.e., if $I_{m}=G_{m}=1$ for all $\mathrm{m}$ ). In this politically influenced case, the typical element of $\tau$ that maximizes (8) can be shown to be

$$
\tau_{m}=\beta-\frac{I_{m}}{a \sigma} .
$$

Three remarks are in order. First, recalling that $\beta \equiv 1-1 / \sigma$ is the first-best subsidy, the subsidy in the lobbying equilibrium equals the utilitarian benchmark only when the government is benevolent $(a=\infty)$ or when no group contributes $\left(I_{m}=0\right.$ for all $\left.m\right)$. Second, (9) shows that the acceptance of contributions induces the government to subsidize a sector beyond the social welfare maximizing level. This allows the sector to sell more as it continues to price monopolistically. Third, as a result of the government payoff functional form, each sector's $\tau_{m}$ depends only on the sector-specific organization variables and parameters, with the subsidy decreasing in the profit margin $1 / \sigma$ and decreasing in the parameter $a$ that measures the government's concern for social welfare. ${ }^{14}$

Characterization of the equilibrium is facilitated because the government's participation constraint is binding only in equilibrium (as usual in the Grossman-Helpman approach). Thus, the $B$-values are chosen by lobbies to make the government just indifferent between allowing $\tau$ to be influenced by accepting contributions and choosing its outside option, which is to refuse contributions from a sector and set that sector's subsidy to the

\footnotetext{
${ }^{13}$ Locally truthful strategies are the only ones to survive the "coalition proofness" refinement introduced in Bernheim et al. (1987).

${ }^{14}$ This is because of the additively separable preferences; generally, all parameters would be relevant.
} 
utilitarian optimum described in (6). That is, assuming all other sectors are lobbying and contributing, sector $m$ 's contribution (which equals $\Pi_{m}-B_{m}$ ) must be large enough to make the government indifferent between accepting its contribution (i.e., choosing $G_{m}=1$ (and thus setting $\tau_{m}=\beta-1 / a \sigma$ ) and refusing its contribution (i.e., choosing $G_{m}=0$ and thus setting $\tau_{m}=$ $\beta$ ). In symbols, the equilibrium $B_{m}$ must satisfy

$$
\begin{aligned}
\Omega^{*}-\Omega^{d e v} & \equiv \frac{a}{1+a} \alpha_{m}\left[\left(\ln \frac{\alpha_{m}}{\beta-1 / a \sigma}-\frac{\beta}{\beta-1 / a \sigma}\right)-\left(\ln \frac{\alpha_{m}}{\beta}-1\right)\right] \\
& +\frac{1}{1+a}\left[\Pi_{m}-B_{m}\right]=0,
\end{aligned}
$$

where $\Pi_{m}$ is evaluated at $\tau_{m}=\beta-1 / a \sigma$. Here $\Omega^{*}$ is the government's payoff in the all-lobby outcome-namely, (8) evaluated at $\tau_{i}=\beta-1 / a \sigma$ for all $i$ with all sectors contributing-and $\Omega^{d e v}$ is the government's payoff when all sectors except sector $m$ contribute (i.e., when $\tau_{i}=\beta-1 / a \sigma$ and $G_{i}=1$ for all $i$ but $m$, and $G_{m}=0$, and $\tau_{m}=\beta$ ).

\section{The Nash equilibrium}

In order to show that the all-lobby outcome is a Nash equilibrium with (9) giving the equilibrium $\tau$-values, we show that a typical sector gains from lobbying when its contribution is large enough to induce the government to accept it. The informal argument is quite simple. A sector's contribution induces the government to choose a policy thatalthough suboptimal from the utilitarian perspective-transfers money from consumers to firms. To respect the participation constraint, a sector's net contribution need only compensate the government for the reduction in social welfare (i.e., the reduction in the $W$ part of $\Omega$ ). Because the social welfare loss is of second order while the transfer is of first order, all sectors will indeed find it in their interests to contribute. Finally, the government is (by construction) just indifferent to deviating from the equilibrium, so its strategy of accepting contributions is Nash. Observe that since the inequality is independent of the state of demand, it follows that both high and low demand sectors would lobby. We summarize this intermediate result as follows.

Result 1: When entry is impossible, the outcome where all sectors lobby regardless of the state of demand is part of a Nash equilibrium. In this all-lobby outcome, the levels of subsidies are given by (9). Moreover, the outcome where lobbying is done only by sectors facing low demand is not a Nash equilibrium.

Proof. The proof of this result boils down to the proof of a simple proposition. By construction, the equilibrium $B$-values are set to induce the government to accept all contributions, and so all we need to show is that a typical sector will want to lobby. To this end, two facts are useful: (i) $\tau_{m}$ equals $\beta-1 / a \sigma$ if sector $m$ lobbies and equals $\beta$ otherwise; and (ii) operating profit is decreasing in $\tau_{m}$ (i.e. increasing in the subsidy rate $1-\tau_{m}$ ). Given these facts, a sector can gain from lobbying provided that the contribution it must pay to the government is sufficiently low. Specifically, denoting the sector- $m$ operating profit function as $\Pi_{m}[\cdot]$, the net profit from lobbying must exceed the net profit from not lobbying: $\Pi_{m}[\beta-$ $1 / a \sigma]-C_{m}>\Pi_{m}[\beta]$. Given that contributions are truthful, our task is then to show that $B_{m}>$ $\Pi_{m}[\beta]$. 
The Nash equilibrium $B_{m}$ is determined by (10), which-using (4) and (9)-can be written as

$$
B_{m}=a \alpha_{m}\left\{\left[\ln \left(\frac{\alpha_{m}}{\tau^{*}}\right)-\frac{\beta}{\tau^{*}}\right]-\left[\ln \left(\frac{\alpha_{m}}{\beta}\right)-1\right]\right\}+\frac{\alpha_{m} / \sigma}{\tau^{*}}, \quad \tau^{*} \equiv \beta-\frac{1}{a \sigma} .
$$

Equation (4) implies that $\Pi_{m}[\beta]=\alpha_{m} / \sigma \beta$, so lobbying is worthwhile to sectors if the following inequality holds:

$$
\begin{aligned}
\Delta & \equiv \alpha_{m} \frac{a}{1+a}\left[\left(\ln \frac{1}{\tau^{*}}-\ln \frac{1}{\beta}\right)-\beta\left(\frac{1}{\tau^{*}}-\frac{1}{\beta}\right)+\frac{1}{a \sigma}\left(\frac{1}{\tau^{*}}-\frac{1}{\beta}\right)\right] \\
& >0 .
\end{aligned}
$$

Observe that either the inequality holds for sectors facing both low and high states of demand, or else it does not hold for any sector.

Because of the $\log$ functions' concavity, $\ln \left(1 / \tau^{*}\right)-\ln (1 / \beta)$ exceeds $\tau^{*}\left(1 / \tau^{*}-1 / \beta\right)$. Substituting this into (12) and rearranging terms, we see that $\Delta$ is greater than something that equals zero:

$$
\Delta>\alpha_{m} \frac{a}{1+a}\left(\tau^{*}-\beta+\frac{1}{a \sigma}\right)\left(\frac{1}{\tau^{*}}-\frac{1}{\beta}\right)=0 .
$$

The right-hand side equals zero by definition of $\tau^{*}$; see (11).

Finally, this reasoning shows that any equilibrium in which some sectors are not lobbying fails to be a Nash equilibrium because each sector would unilaterally gain from lobbying. QED.

\section{Entry and the incentive to lobby}

We now extend the model to continuous time and allow the number of firms in a typical sector to be determined via free entry.

\subsection{Additional assumptions}

The representative agent maximizes her lifetime utility, which is assumed to be additively separable and equal to $\int_{t=0}^{\infty} e^{-r t} U \mathrm{~d} t$, where $U$ is as in (1) and $r>0$ is the discount rate. The representative agent can choose either to consume her income or to invest it in shares of new firms. Preferences are random; the switching between $\alpha_{L}$ and $\alpha_{H}$ is governed by a symmetric Markov process (see Table 1).

Creation of a new industrial firm in any of the $M$ sectors entails a fixed cost consisting of one unit of capital (this cost reflects market entry costs as in Baldwin's (1988) model). One unit of capital is produced from $F$ units of labor under conditions of perfect competition, so the entry cost equals $F$. Importantly, this capital is sunk in the following sense: once a unit of capital is built, it must be either employed in the sector in which it was invested or 
abandoned (since all consumers are identical, no firms will be sold in equilibrium). In addition, capital does not depreciate. ${ }^{15}$

Our next task is to characterize the entry decision.

\begin{tabular}{|c|c|c|}
\hline Transition probabilities & $\alpha_{L}$ & $\alpha_{H}$ \\
\hline$\alpha_{L}$ & $1-\lambda \mathrm{d} t$ & $\lambda \mathrm{d} t$ \\
\hline$\alpha_{H}$ & $\lambda \mathrm{d} t$ & $1-\lambda \mathrm{d} t$ \\
\hline
\end{tabular}

Table 1: The Markov transition matrix

\subsection{Entry}

Entry, as usual, is assumed to occur instantaneously and up to the point where the equilibrium value of firms is no greater than the entry cost $F$. Owing to the stochastic demand, a single firm will have different values depending on the current state of demand (high versus low).

\section{Value of the firms at steady-state}

The value $V$ of a typical firm in a typical sectoris the discounted value of operating profits net of any lobbying contribution. ${ }^{16}$ By symmetry, there are only two levels of $V$ : one for firms belonging to low-demand sectors, $V_{L}$, and one for firms belonging to high-demand sectors, $V_{H}$. Specifically,

$$
\begin{aligned}
& V_{L}=b_{L} \mathrm{~d} t+e^{-r d t}\left[\lambda \mathrm{d} t V_{H}+(1-\lambda \mathrm{d} t) V_{L}\right], \quad b_{L}=\left(\Pi_{L}-I_{L} C_{L}\right) / N, \\
& V_{H}=b_{H} \mathrm{~d} t+e^{-r d t}\left[\lambda \mathrm{d} t V_{L}+(1-\lambda \mathrm{d} t) V_{H}\right], b_{H}=\left(\Pi_{H}-I_{H} C_{H}\right) / N,
\end{aligned}
$$

where we omit the time and sector subscripts since these values are constant at steady state and since sectors face either high or low demand. Note that the values for $b$ (a mnemonic for benefit) are the per-firm operating profit net of any contributions, so $b_{i}=B_{i} / N$, for $i=H, L$.

These equations are easy to interpret. For $V_{L}$, the value of a firm in state $L$ at time $t$ is equal to the current flow of net profits plus the expected discounted value it will have at time $t+\mathrm{d} t$ : with probability $\lambda \mathrm{d} t$ it will move to state $H$ and with probability $1-\lambda \mathrm{d} t$ it will remain in state $L$. The value $V_{H}$ is defined analogously. In the limit of continuous time as $\mathrm{d} t \rightarrow 0$, by symmetry among industries and firms within industries we have, after rearranging:

\footnotetext{
${ }^{15}$ Adding depreciation is uncomplicated (see Section 4.3) but is not necessary here.

${ }^{16}$ As a special feature of our functional forms, total operating profit per sector is independent of the number of firms per sector; the key point is that $V$ is diminishing in $N$.
} 
(14)

$$
\begin{aligned}
r V_{L} & =b_{L}+\lambda\left(V_{H}-V_{L}\right), \quad r V_{H}=b_{H}-\lambda\left(V_{H}-V_{L}\right) \\
& \Leftrightarrow \\
V_{L} & =\frac{(r+\lambda) b_{L}+\lambda b_{H}}{r(r+2 \lambda)}, \quad V_{H}=\frac{(r+\lambda) b_{H}+\lambda b_{L}}{r(r+2 \lambda)} .
\end{aligned}
$$

The first two expressions are standard asset-pricing equations: $r$ times the expected value of the firm must equal the sum of the current flow of net profits and the expected capital gain. The latter two expressions are the solutions for each $V$ in terms of $b$.

Because the cost of entry is $F$, free-entry requires that the steady state number of firms per sector rises until the maximum value of a typical firm equals $F$. A firm's value may differ between high- and low-demand states; hence the entry condition is

$$
N \text { subject to } \max \left\{V_{H}, V_{L}\right\}=F \text {. }
$$

Note that $U$ in (1) is quasi-linear, so the transition dynamics are degenerated. That is, $N_{m}$ jumps to its steady-state value $N^{*}$ as soon as $\alpha_{m}=\alpha_{H}$. (It jumps to some $N_{0}<N$ if $\alpha_{m}=\alpha_{L}$ initially, as we shall explain).

\subsection{The only-losers-lobby equilibrium}

We assert that the outcome in which only sectors facing low demand lobby is a Markov perfect equilibrium (MPE), and we refer to it as the "only losers lobby" (OLL) outcome. In this dynamic version of the model, the state variables are (i) $N$, the number (mass) of firms in a typical sector-a number that is influenced by players' actions via free entry-and (ii) $\alpha$, the vector of the states of demand facing each sector. Given our simple setup, a sector's strategy can be summarized by its decision on whether or not to lobby, with this action possibility depending upon the state of demand. Formally, the OLL equilibrium can be expressed as the set of sector strategies such that

$$
I_{m}=\left\{\begin{array}{lll}
0 & \text { if } & \alpha_{m}=\alpha_{H}, \\
1 & \text { if } & \alpha_{m}=\alpha_{L} .
\end{array}\right.
$$

Here $I_{m}=1$ or $I_{m}=0$ indicates that sector $m$ is or (respectively) is not lobbying. Note that since there is irreversible entry and since Dixit-Stiglitz monopolistic competition never produces negative operating profit (Dixit and Stiglitz 1977), the number of firms that are active in each sector is constant in steady state. This and symmetry of firms allows us to drop the sector subscript from the $N$-terms. In this outcome, the values of a typical firm are

$$
\begin{aligned}
V_{L}^{O L L} & =\frac{b_{L}(r+\lambda)+\lambda b_{H}}{r(r+2 \lambda)}, \quad V_{H}^{O L L}=\frac{b_{H}(r+\lambda)+\lambda b_{L}}{r(r+2 \lambda)} ; \\
b_{L} & =\frac{1}{N}\left(\frac{\alpha_{L}}{\sigma(\beta-1 / a \sigma)}-B\right), \quad b_{H}=\frac{\alpha_{H}}{\sigma \beta N} .
\end{aligned}
$$

The superscript "OLL" is used to denote the value of firms in sectors implementing the only-losers-lobby strategies.

To demonstrate that the OLL outcome is an MPE, it is useful first to establish that, for any given $N$, the value of a firm when it faces low demand is no greater than its value when it 


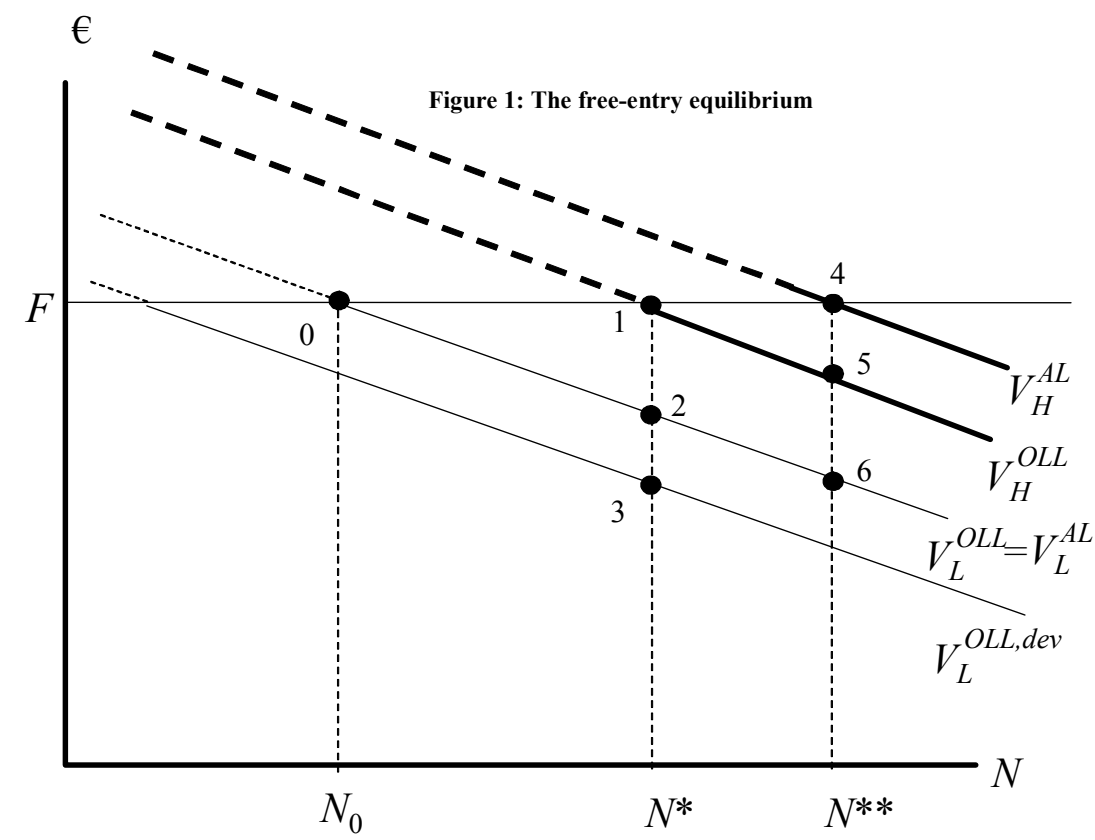

faces high demand; that is, $V_{L}^{O L L} \leq V_{H}^{O L L}=F$. This feature is intuitively obvious and easy to establish formally. ${ }^{17}$

Figure 1 helps us interpret the equilibrium by plotting values of a typical firm against the number of firms per sector. Since competition lowers per-firm value, all lines slope downward. The second and third lines (counting from the top) indicate the only-losers-lobby outcome for sectors facing high and low demand. These are marked $V_{H}^{O L L}$ and $V_{L}^{O L L}$, respectively; the $V_{H}^{O L L}$ line is above the $V_{L}^{O L L}$ line. Free entry means that the value of a firm can never rise above $F$, so all the value lines are cut off at the horizontal line at $F$. Plainly, the steady-state number of firms is $N^{*}$ in the OLL outcome. The value of firms facing high demand will be $F$; point 2 gives the value of firms facing low demand.

\section{Establishing the Markov perfect equilibrium}

Using the diagram, we can show that the only-losers-lobby outcome is a Markov perfect equilibrium. We start with the government. At every time $t$, the government cannot, by construction of $B$, gain from deviating from the OLL outcome. Thus, accepting contributions and providing the politically influenced $\tau$ is part of a Nash equilibrium in every subgame and in every state of the world. The argument for high-demand sectors is similar. No highdemand sector could gain from deviating; after all, free entry ensures that the value of a typical firm cannot rise above $F$, so any lobbying effort would be useless. Thus, the strategy of no lobbying in high-demand states is Nash in every subgame.

Finally, low-demand sectors cannot gain from deviating because ceasing to lobby would lower their value from point 2 to point 3 in the diagram. More specifically, under this deviation the value of a typical firm facing low-demand sector would be $\left[\lambda b_{H}+(r+\lambda) b_{L}^{d e v}\right] /[r(r+2 \lambda)]$, where $b_{L}^{d e v}$ is the per-firm operating profit in the low-demand

\footnotetext{
${ }^{17}$ The proof is by contradiction. If $V_{L}^{\mathrm{OLL}}>V_{H}^{\mathrm{OLL}}$ then the free entry condition implies $F=V_{L}^{\mathrm{OLL}}$, so $F>V_{H}^{\mathrm{OLL}}$. This in turn implies that the high-demand sector could lobby without attracting entry and so, by Result 1 , it would. Since this contradicts the definition of the only-losers-lobby outcome, we know that $V_{L}^{\mathrm{OLL}} \leq V_{H}^{\mathrm{OLL}}=\mathrm{F}$. This in turn implies $b_{L} \leq b_{H}$.
} 
state when the subsidy is the socially optimal $\beta$ (i.e., when $b_{L}^{d e v}=\alpha_{L} /(\sigma \beta N)$ ). The proof of Result 1 showed that one-period lobbying is always worthwhile when it does not change $N$, so we know that $b_{L}=\left\{-B+\alpha_{L} /[\sigma(\beta-1 / a \sigma)]\right\} / N$ exceeds $b_{L}^{d e v}$. Using (14) this tells us that not lobbying in the low-demand state would lower the typical firm's value.

We summarize these findings in our next result.

Result 2: Because free entry makes lobbying useless for sectors facing their entry margin (i.e., for high-demand sectors), the only-losers-lobby outcome is a Markov perfect equilibrium. However, firms in sectors facing low demand find their values below entry costs, so lobbying can raise their value.

As it turns out, the OLL outcome is not the only MPE, as Grossman and Helpman (1996) have pointed out.

\subsection{Other equilibria}

Starting from $N=N^{*}$, lobbying in the high state does no good-but neither does it harm firms facing high demand. If (for whatever reason) incumbents in a sector with high demand actually did lobby, this would induce more entry and thus an increase in the equilibrium number of firms to $N^{* *}$ in the diagram. It is important to note that, once the new entrants are irreversibly in the market, a deviation by cessation of lobbying in the high-demand state would lower the value of the firm from point 4 to 5 in the diagram, so no deviation would occur in the high-demand state. Likewise, no deviation would occur in the low-demand state, so this outcome-what we call the "all lobby" outcome, denoted as "AL" in the diagram-is also an MPE. We summarize this as follows:

Result 3: Given free entry, the all-lobby outcome is a Markov perfect equilibrium because, once high-demand lobbying has increased the number of active firms, cessation of lobbying would lower the value of such firms. As before, sectors facing low demand can raise their value by lobbying, so lobbying in both states is also a MPE.

It is possible to arrive at the $N=N^{* *}$ state because lobbying in the high-demand state starting from $N=N^{*}$ is both useless and costless in terms of incumbent firms' value in the high-demand state.

\section{Dominance of only-losers-lobby MPE}

Although this second MPE does exist, there are good reasons for believing that it would never occur. The basic argument is that, even though the increase in the number of firms from $N^{*}$ to $N^{* *}$ does not affect $V_{H}$, it will lower the value of firms facing low-demand returns. Note that the value of a typical firm facing high demand is identical (namely $F$ ) in the two MPEs, but the value of a typical firm facing low-demand is lower in the all-lobby outcome. To see this, observe that from (14) with $V_{H}=F$, we have $V_{L}{ }^{i}$ equals $\left(b_{L}{ }^{i}+\lambda F\right) /(r+\lambda)$, where $i$ denotes either "OLL" (in the only-losers-lobby equilibrium) or "AL" (in the all-lobby equilibrium). Since $b_{L}$ is given by (16) with $\alpha_{m}=\alpha_{L}$ and since $N^{* *}>N^{*}$, it is clear that $V_{L}^{A L}$ is

lower than $V_{L}^{O L L}$ (these values correspond to points 2 and 6 in the diagram). In short, although the lobbying-induced entry has no effect on the value of firms facing high demand, the presence of more firms lowers the value of the same firms in the low-demand state. Our next result summarizes this reasoning. 
Result 4: The only-losers-lobby and all-lobby outcomes are both MPEs, but the former dominates the latter in the sense that firms are indifferent between the two when facing high demand yet strictly prefer the OLL equilibrium when facing low demand. This makes the only-losers-lobby MPE focal.

\section{Extensions}

In this section we consider three extensions of our analysis. We first allow for the possibility that new entrants "free ride" on the lobbying contributions by former incumbents for some time. We then show that assuming technological shocks yields the same qualitative results as in the case of demand shocks described thus far. Finally, we apply our model to sunset industries-namely, for the case of permanent adverse shocks.

\section{1. $\quad$ Free riding}

In the spirit of the Grossman-Helpman lobbying approach, our basic model assumes that all firms in a sector are politically perfectly organized in the sense that they act as one when it comes to presenting and financing a contribution menu to the government. To deal with entry, we extend our basic model in the simplest possible way: by supposing that all entrants immediately act as incumbents. This of course is not the only reasonable assumption (see Grossman and Helpman 1996 for discussion of the issue) and, as we shall see, relaxing this assumption has important implications for Result 3.However, we shall demonstrate that this assumption does not alter (and even reinforces) our main result that free entry removes the incentive for lobbying in sectors facing their entry margin, since when profits are above the standard value they are immediately and successfully grabbed by entrants.

\section{Modeling free riding}

To model free riding by entrants, we assume that new firms do not share the financing of contributions initially but that they do become perfectly organized (i.e., act identically to incumbents) eventually. Specifically, all newly entered firms start as free riders but switch into non-free riders (i.e., join the perfectly organized firms) according to a Poisson process marked by the hazard rate $\phi$. This switch is synchronized across all entrants in the sense that at any given time, new entrants either will all be free riders or will all be non-free riders. Furthermore, we assume that the switch to non-free rider status is permanent, so that eventually all firms are perfectly organized. Observe that $\phi$ provides a natural parameter for the extent of the free-riding problem since newcomers are expected to remain free riders for a period equal to $1 / \phi$. Our basic model implicitly assumes that $\phi$ is infinite.

We begin by studying the all-lobby outcome, that is, where both high- and lowdemand sectors lobby. Free riding complicates the calculation of the expected value of entering because we must take account of the probabilities that (i) the sector sees its demand change and (ii) the entrant experiences a shift in its free-riding status. Incumbent firms in this case will have one of four possible values: $V_{H, u}, V_{L, u}, V_{H}$ or $V_{L}$. These are, respectively, the value of an incumbent facing high or low demand when entrants are unorganized (as shown by the subscript $u$ ) and when the entrants have joined the lobby (as shown by a lack of the subscript).

Three instantaneous probabilities are relevant to an incumbent's value. These are: 
(i) the probability that the sector experiences a shift in demand, $\lambda \mathrm{d} t$;

(ii) the probability that entrants become non-free riders, $\phi \mathrm{d} t$;

(iii) the probability that the sector experiences both a change in demand and entrants become non-free riders, $\lambda \phi(\mathrm{d} t)^{2}$.

Taking account of these at the limit $\mathrm{d} t \rightarrow 0, V_{H}$ and $V_{L}$ are still determined by (14); the expected values of an incumbent in the various states when entrants are unorganized are then

$$
\begin{aligned}
& r V_{H, u}=b_{H, u}-\lambda\left(V_{H, u}-V_{L, u}\right)-\phi\left(V_{H, u}-V_{H}\right), \\
& r V_{L, u}=b_{L, u}+\lambda\left(V_{H, u}-V_{L, u}\right)-\phi\left(V_{L, u}-V_{L}\right),
\end{aligned}
$$

where the values of $b$ are the "flow rewards" to incumbents in the various states (see Appendix A.2 for computational details).

The related value equations for entrants are:

$$
\begin{aligned}
& r J_{H}=\pi_{H}-\lambda\left(J_{H}-J_{L}\right)-\phi\left(J_{H}-V_{H}\right), \\
& r J_{L}=\pi_{L}+\lambda\left(J_{H}-J_{L}\right)-\phi\left(J_{L}-V_{L}\right),
\end{aligned}
$$

where $J_{H}$ and $J_{L}$ are the values of free-riding firms when the sector under evaluation is facing high and low demand, respectively.

Since free riders do not contribute to lobbying expenses, the flow benefit of being a free rider in both the high and low states of demand exceeds the flow benefit of being an incumbent:

$$
\pi_{H}-b_{H, u} \equiv \gamma_{H}>0, \quad \pi_{L}-b_{L, u} \equiv \gamma_{L}>0,
$$

where $\gamma_{H}$ and $\gamma_{L}$ are constants.

The free-entry condition in this extension is $J_{H}=F$.

\section{Would high-demand incumbents lobby?}

In the basic model, incumbents in the high-demand sector were indifferent to lobbying when $N=N^{*}$, since lobbying neither brought them any benefits nor harmed their value. Now we turn to evaluating whether high-demand sectors would still be indifferent to lobbying.

Section 3 established that the value of high-demand incumbents in the only-loserslobby outcome was equal to $F$. To see whether high-demand sectors would be indifferent to lobbying, we check whether the value of incumbents at the moment they lobby-that is, at the instant of entry when entrants are still free riders, namely $V_{H, u}$ from (18)-is less than $F$. Toward this end we solve (18) and (19) for the values of incumbents in the four possible states of the world (high or low demand and entrants free riding or not). The solutions, though intuitive, are not especially transparent, but for our purpose we need only consider the difference $J_{H}-V_{H, u}$, which can be written as (see Appendix A.2. for details)

$$
J_{H}-V_{H, u}=\frac{(r+\phi+\lambda) \gamma_{H}+\phi \gamma_{L}}{(r+\phi)(r+\phi+2 \lambda)} .
$$

Given (20), we know that this expression is positive for any finite $\phi$. Moreover, this difference tends to zero as $\phi$ approaches infinity.

What this reasoning shows is that, starting from $N=N^{*}$, incumbents facing high demand in the OLL outcome would never agree to lobby if there were any chance that free 
entrants would free ride, even for an infinitely short time. This result reinforces our assertion that the only-losers-lobby outcome is focal. ${ }^{18}$

\subsection{Technology shocks instead of demand shocks}

The basic model assumes stochastic preferences in order to generate stochastic demand functions. In this section, we show that nothing would change by instead assuming stochastic technology. Hence, we assume that the sector-specific marginal costs are random variables $\beta_{m}$ that are independently and identically distributed across sectors. Specifically, $\beta_{m} \in\left\{(1-1 / \sigma) \beta_{G},(1-1 / \sigma) \beta_{B}\right\}$ for all $m$, where $\beta_{G}<\beta_{B} ; G$ is a mnemonic for good and $B$ stands for bad. Under Dixit-Stiglitz monopolistic competition and within-sector symmetry, the price charged by all sector- $m$ firms is $\beta_{m} /(1-1 / \sigma)$.

Moreover, we introduce some substitutability across sectors by assuming that preferences are $U=A+\left(\sum_{m=1}^{M} D_{m}^{1-1 / \theta}\right)^{1 /(1-1 / \theta)}, \theta>1$. Given the law of large numbers, total expenditure on sector $m$ 's varieties is

$$
N p_{m} c_{m}=\frac{\left(\tau_{m} \beta_{m}\right)^{1-\theta}}{(M / 2)\left(\tau_{G} \beta_{G}{ }^{1-\theta}+\tau_{B} \beta_{B}^{1-\theta}\right)} .
$$

Now redefining $\alpha_{H}$ and $\alpha_{L}$ as equal to the right-hand side of expression (22) evaluated at $\beta_{m}$ equal to $(1-1 / \sigma) \beta_{G}$ and $(1-1 / \sigma) \beta_{B}$, respectively, we note that the relation $\alpha_{H}>\alpha_{L}$ still holds and hence all other derivations in the paper carry through unaltered.

\subsection{Sunset industries}

As we stated in the Introduction, the literature on sunset industries highlights that these industries continue to decline despite the protection they receive, assuming they get protection in the first place. A simple extension of our model captures this idea; note that our model allows for endogenous lobbying decisions, so we do not assume that these industries are protected a-priori. ${ }^{19}$

We first assume that firms are "dying" at a Poisson rate $\delta$, so that $N$ can decrease as well as increase. Next, for simplicity we still assume that the shocks occur on demand. But now we assume that once a negative shock has hit industry $m\left(\alpha_{m}=\alpha_{L}\right)$, demand will not recover. In other words, shocks are permanent (and the cells of the first row of Table 1 now contain the numbers 1 and 0 , respectively; that is, the low state of the world is an absorbing state). Together, these modifications imply that equation (14) must be replaced by

\footnotetext{
${ }^{18}$ The idea here is akin to the "trembling hand" refinement. If incumbents did make a mistake and lobbied in the high state, thus raising the number of firms to the point where $J_{H}=F$, then they would continue to lobby because doing otherwise would lower their value even further. This result, however, relies on the lack of exit. If firms did exit, a one-time mistake would be corrected eventually. We thank Thierry Verdier for this observation.

${ }^{19}$ In this case also, two Markov perfect equilibria exist: the looser-only-lobby MPE and the all-lobby MPE. Using an argument similar to that in Section 3.4, we can claim that the former is focal: $V_{H}$ is equal to $F$ in both MPEs, but $V_{L}$ is larger in the former than in the latter.
} 
(23)

$$
\begin{aligned}
& (r+\delta) V_{L}=b_{L}, \quad(r+\delta) V_{H}=b_{H}-\lambda\left(V_{H}-V_{L}\right) \\
& \Leftrightarrow \\
& V_{L}=\frac{b_{L}}{r+\delta}, \quad V_{H}=\frac{b_{L}}{r+\delta}+\frac{b_{H}-b_{L}}{r+\delta+\lambda},
\end{aligned}
$$

where (as before) $V_{H}>V_{L}$ holds without ambiguity whenever $b_{H}>b_{L}$.

The free-entry condition (15) implies $V_{H}=F$, which once again pins down the equilibrium number of firms. We call it $N^{*}$ so that Figure 1 illustrates the present extension as well. In particular, we concentrate on the MPE in which only losers lobby. Note that dying firms are immediately replaced by new entrants, so $N=N^{*}$ as long as $\alpha=\alpha_{H}$.

Consider now what happens when, at some random time $T$, demand falls permanently to $\alpha_{L}$. At time $T$, the number of firms $N^{*}$ implies that the value of each firm in the affected sector falls to $V_{L}^{O L L}<F$. In words, despite the fact that firms in this sector are now lobbying, their value is smaller than the opportunity cost of capital and so no new firms will enter the sector. What is new is that the mass of firms is now decreasing at a rate $\delta$, so that $V_{L}^{O L L}$ increases over time (remember that $b_{L}=B_{L} / N$ and that $B_{L}$ is constant). This suggests that $N$ and $V_{L}^{O L L}$ evolve over time as plotted in Figure 2 below.

Figure 2 plots time on the horizontal axis and, on the vertical axis, plots both the number of firms and the value of a typical firm in a representative sunset industry. Assume now that this sector is hit by the shock at time $T$. First, as can be seen in the figure, $V_{L}^{O L L}$ "overshoots" at the time of the shock. Second, as the number of firms shrinks over time, $V_{L}^{O L L}$ returns to its steady-state value. At time $T+\Delta T, V_{L}^{O L L}=F$ is expected to hold again and the number of firms no longer changes: $N=N_{0}{ }^{20}$

\footnotetext{
${ }^{20}$ More formally, for any $\varepsilon \in \mathbf{R}_{++}$and for any $\xi \in \mathbf{R}_{++}$, there exists a positive real number $\Delta T$ such that $0 \leq F-V_{L}^{O L L}(t)<\varepsilon$ and $0 \leq N(t)-N_{0}<\xi$ for all $t \geq T+\Delta T$.
} 


\section{Figure 2: Sunset industries}

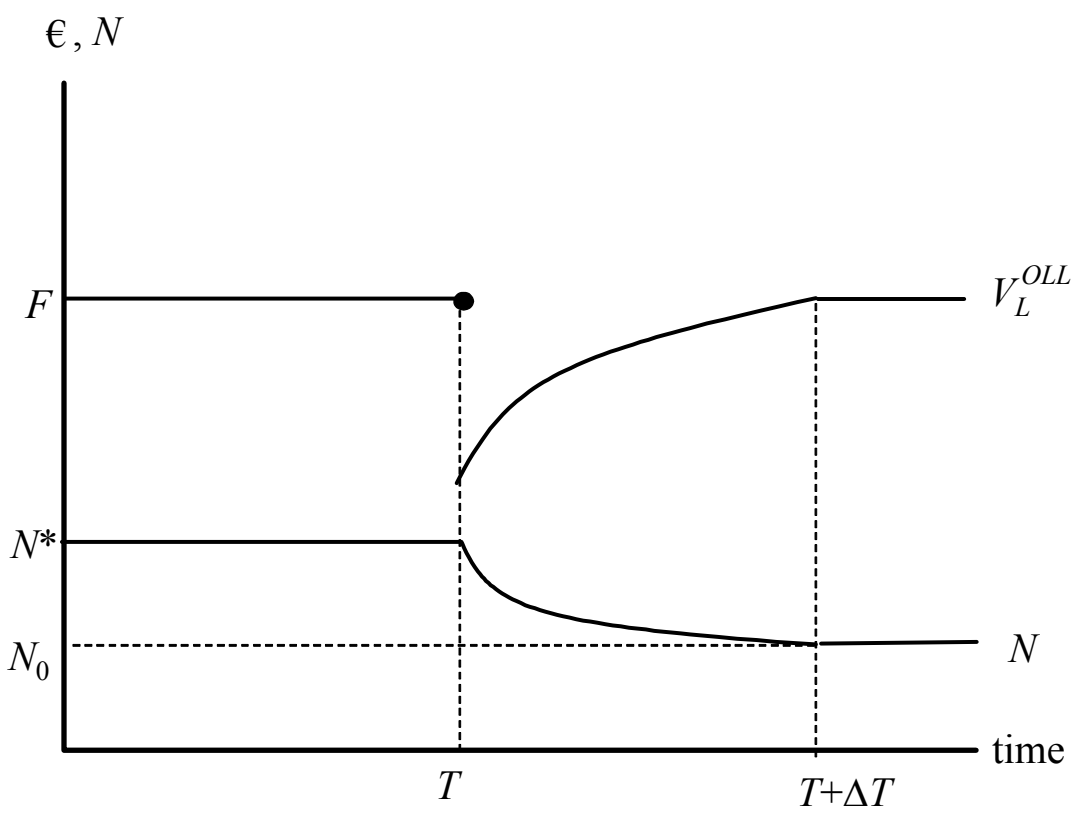

To capture more fully the idea that the industry is a "sunset industry", assume now that $\alpha$ keeps falling over time at random intervals without ever reaching 0 . Namely, the values of $\alpha$ now form an infinite sequence $\alpha_{H} \equiv \alpha_{1}>\alpha_{2}>\cdots>\alpha_{J}>\alpha_{J+1}>\cdots>0$ and the Markov square matrix has now an infinitely countable number of rows and columns with identical terms $1-\lambda \mathrm{d} t$ along the main diagonal, $\lambda \mathrm{d} t$ in each cell to the left of the main diagonal, and zeroes everywhere else. Then $N_{0}(\alpha)$, the steady-state mass of firms given $\alpha<\alpha_{\mathrm{H}}$, keeps falling. Note however that $N_{0}(\alpha)>0$ for all $\alpha>0$.

This "tomorrow never dies" feature of the model is not the most attractive, but it is a direct consequence of the fact that Dixit-Stiglitz monopolistic competition never produces negative operating profits. With more reasonable assumptions, there would exist a threshold $\alpha$, call it $\alpha_{0}$, at which $N_{0}\left(\alpha_{0}\right)<0$. In such a case, all firms would have leave the sector eventually.

To sum up the results of this section, we observe that a sector hit by a permanent shock gets protection at equilibrium; yet despite the protection received, this sector shrinks (there is a net exit of firms) over time and, under reasonable assumptions, this sector eventually disappears. We remark that the "sunset sector" would have disappeared earlier if it could not successfully lobby the government for protection. This suggests that the possibility of lobbying entails hysteresis of the production mix at the aggregate level. Since successful, growing sectors do not lobby, this might-in a proper general equilibrium model-reduce growth or steady-state per capita incomes. (See also Grossman and Helpman 1996 on this point.) 


\section{Conclusion}

Despite differences in political institutions and laws, declining industries account for the bulk of protection granted in all industrialized nations. The GATT also asymmetrically favors ailing industries. This asymmetry is curious because selfish governments should be equally interested in the lobbying dollars of expanding and declining industries. Our paper provides a political equilibrium explanation based on sunk entry costs. We assume that industries spend money on lobbying to obtain profit-boosting protection and note a strong asymmetry between the appropriability of protection in contracting and expanding industries. In expanding industries, rents attract new entrants that erode the rents, but this is not true in ailing industries. Sunk entry costs (product development, training, advertising, etc.) allow protection to raise profits without attracting entry-as long as profits rise to a value not higher than a normal return on sunk capital. Clearly, asymmetric appropriability implies asymmetric lobbying, and the result is that losers get most of the protection because losers lobby harder.

\section{Policy implications}

The analysis in our paper can also be used to shed light on the social desirability of packaging protectionist policies with anti-entry policies (such as a government monopoly or production quotas). Such packaging is likely to lead to greater levels of protection because it increases the incentives of all industries to lobby for protection. Consider, for instance, an industry that is able to organize a cartel that prevents new production and entry. Since entry is impossible, all sectors-both expanding and contracting-will find that lobbying generates appropriable rents. As Result 1 showed, all sectors will lobby and the overall outcome will be a greater reduction in social welfare than would occur without the entry barriers.

Most OECD countries have laws prohibiting this kind of collusion; however, in certain industries such as medicine, the special interest group itself regulates the flow of new entrants via control over standards. Labor unions could serve a similar role. In the basic model described here, labor was paid the going wage and all rents accrued to firm owners. However, it is easy to imagine a model where an industry-specific labor union manages to capture some or all of the rents created by protection. In such a model, the labor unions that are able to control the wage of new workers would benefit from higher tariffs in expanding industries. In fact, many countries do (or did) sanction "closed shop" rules that have exactly this effect. Alternatively, the fixed setup cost can also be interpreted as investments in human capital; under this interpretation, the model would explain why workers with skills specific to ailing industries would lobby.

One obvious policy recommendation derives directly from this analysis. Protectionist packages that place controls on domestic entry or production are likely to attract greater lobbying efforts and thereby lead to greater deviations from the social optimum. Consequently, prohibiting such packaging of policies would lower equilibrium protection rates. 


\section{Appendix}

\section{A.1. Deriving equation (5)}

In this appendix, we derive the government's reduced form objective function (5) in the text. From the industry demand functions, assuming symmetry of varieties within an industry and $p=1$ (which itself follows from markup pricing and choice of numéraire and units), we have

$$
D_{m} \equiv\left(N_{m}^{-1 / \sigma} \int_{j}\left(\frac{\alpha_{m}}{N_{m} \tau_{m}}\right)^{1-1 / \sigma} \mathrm{d} j\right)^{1 /(1-1 / \sigma)}=\frac{\alpha_{m}}{\tau_{m}} .
$$

Hence, the second term in the utility function reduces to

$$
\sum_{m=1}^{M} \alpha_{m} \ln D_{m}=\sum_{m=1}^{M} \alpha_{m} \ln \left(\frac{\alpha_{m}}{\tau_{m}}\right)
$$

As usual with quasi-linear utility, spending on $A^{c}$ is a residual and so the total demand for $A$, aggregating over all consumers, is

$$
\begin{aligned}
A^{c} & =Y-T-\sum_{m=1}^{M} N_{m} p \tau_{m} c_{m} ; \\
Y & =1+\sum_{m=1}^{M} N_{m} \frac{\alpha_{m}}{N_{m} \sigma \tau_{m}} ; \quad T=\sum_{m=1}^{M} N_{m} p c_{m}\left(1-\tau_{m}\right) .
\end{aligned}
$$

Here we have used the balanced budget assumption to define the level of lump sum taxation, $T$. Aggregate consumer income $Y$ equals labor income (i.e., unity) plus all operating profits-which, given (4), are equal to the second right-hand term in the expression for $Y$. Combining these elements and using $p=1$ yields

$$
A^{c}=1+\frac{1}{\sigma} \sum_{m=1}^{M} N_{m} \frac{\alpha_{m}}{N_{m} \tau_{m}}-\sum_{m=1}^{M} N_{m} c_{m}=1+\left(\frac{1}{\sigma}-1\right) \sum_{m=1}^{M} \frac{\alpha_{m}}{\tau_{m}},
$$

where we have used symmetry to obtain $c_{m}=\alpha /\left(N_{m} \tau_{m}\right)$ and thus the final expression on the right-hand side. Then, combining these expressions for $A^{c}$ and $D_{m}$ we obtain expression (5) in the text.

To boost intuition and facilitate graphical representation of the model, it is useful to rewrite $W$ as

$$
W=\frac{a}{1+a}\left\{1+\sum_{m=1}^{M} \Pi_{m}+\sum_{m=1}^{M} N_{m}\left(\alpha_{m} D_{m}-p c_{m}\right)\right\} .
$$

That is to say, indirect utility of consumers (and thus the utilitarian social welfare function) is proportional to 1 plus the sum of operating profit plus the sum of consumer surplus. 


\section{A.2. Deriving equation (21)}

In order to understand how we derive the expressions in (18), first note that $V_{H, u}$ for any $\mathrm{d} t$ can be written as

(A.6)

$$
\begin{aligned}
V_{H, u}= & b_{H, u} \mathrm{~d} t+e^{-r \mathrm{~d} t}\left\{V_{L, u} \lambda \mathrm{d} t+V_{H} \phi \mathrm{d} t\right. \\
& \left.+V_{L} \phi \lambda(\mathrm{d} t)^{2}+\left[1-\lambda \mathrm{d} t-\phi \mathrm{d} t-\phi \lambda(\mathrm{d} t)^{2}\right] V_{H, u}\right\} .
\end{aligned}
$$

Rearranging and dividing all terms by $\mathrm{d} t$ then gives

$$
\begin{aligned}
\frac{1-e^{-r \mathrm{~d} t}}{\mathrm{~d} t} V_{H, u} & =b_{H, u}+e^{-r \mathrm{~d} t}\left[\left(V_{L, u}-V_{H, u}\right) \lambda\right. \\
& \left.+\left(V_{H}-V_{H, u}\right) \phi+\left(V_{L}-V_{H, u}\right) \phi \lambda \mathrm{d} t\right] ;
\end{aligned}
$$

now, taking the limit $\mathrm{d} t \rightarrow 0$ yields the result in (18).

The system given by (18) and (19) can be rewritten so as to solve for $J_{H-} V_{H, u}$ and $J_{L^{-}}$ $V_{L, u}$-namely, for the differences between the payoff of the free-riders and of the contributors in each state:

(A.8)

$$
\left[\begin{array}{cc}
r+\phi+\lambda & -\lambda \\
-\lambda & r+\phi+\lambda
\end{array}\right]\left[\begin{array}{c}
J_{H}-V_{H, u} \\
J_{L}-V_{L, u}
\end{array}\right]=\left[\begin{array}{c}
\gamma_{H} \\
\gamma_{L}
\end{array}\right]
$$

where we have made use of (20). Using Cramer's rule, it is now easy to derive (21). Note also that the term $V_{H}-V_{L}$ does not appear in the system (A.8); rather, it is determined by (14). 


\section{References}

Baldwin, Richard E. (1987). "Politically Realistic Objective Functions and Trade Policy: PROFs and Tariffs." Economic Letters, 24, pp. 287-290.

Baldwin, Richard E. (1988). "Hysteresis in Import Prices: The Beachhead Effect." American Economic Review, 78, pp. 773-785.

Baldwin, Richard E. (1993). “Asymmetric lobbying effects: Why governments pick losers." Mimeo, Graduate Institute of International Studies on http://heiwww.unige.ch/ baldwin/.

Baldwin, Richard E., Virginia Di Ninio and Frédéric Robert-Nicoud (2006). "Asymmetric lobbying effects: Evidence from the US.” Processed, Graduate Institute of International Studies and LSE.

Baldwin, Richard E. and Frédéric Robert-Nicoud (2006). "Protection for Sale made easy." CEPR discussion paper \#5452.

Baldwin, Robert E. (1982). “The political economy of protectionism.” In Import Competition and Response, edited by Jagdish Baghwati. University of Chicago Press.

Baldwin, Robert E. (1985). The Political Economy of US Import Policy. Cambridge MA: MIT Press.

Baldwin, Robert E. and Jeffrey Steagall (1994). "An analysis of factors influencing ITC decisions in antidumping, countervailing duty and safeguard cases."

Weltwirtschaftliches Archiv 130, pp. 290-308.

Bernheim, Douglas B., Bezalel Peleg and Michael D. Whinston (1987). "Coalition-proof Nash equilibria I. Concepts." Journal of Economic Theory, 42, pp. 1-12.

Bernheim, Douglas B. and Michael D. Whinston (1986). "Menu auctions, resource allocation, and economic influence." Quarterly Journal of Economics, 101, pp. 1-31.

Bohara, Alok and William Kaempfer (1991). "A test of tariff endogeneity in the US." American Economic Review, 81, pp. 952-960.

Brainard, Lael and Thierry Verdier (1997). "The political economy of declining industries: Senescent industry collapse revisited." Journal of International Economics, 42, pp. 221-237.

Cassing, James and Arye Hillman (1986). "Shifting comparative advantage and senescent industry collapse.” American Economic Review 76, pp. 516-523.

Corden, Max (1974). Trade Policy and Economic Welfare. Oxford: Oxford University Press.

Dixit, Avinash K., Gene Grossman and Elhanan Helpman (1997). "Common agency and coordination: General theory and application to government policy making." Journal of Political Economy, 105, pp. 752-769.

Dixit, Avinash K. and Joseph Stiglitz (1977). "Monopolistic competition and the optimum product diversity." American Economic Review, 67, pp. 297-308. 
Felli, Leonardo and Antonio Merlo (2006). "Endogenous lobbying." Journal of the European Economic Association, 4, pp. 180-215.

Fernandez, Raquel and Dani Rodrik (1991). "Resistance to reform: Status quo bias in the presence of individual-specific uncertainty." American Economic Review, 81, pp. $1146-1156$.

Findlay, Ronald and Stanislaw Wellisz (1982). "Endogenous tariffs, the political economy of trade restrictions and welfare." In Important competition and response, edited by Jagdish Bhagwati. Chicago: Chicago University Press.

Flam, Harry and Elhanan Helpman (1987). "Industrial policy under monopolistic competition.” Journal of International Economics, 22, pp. 79-102.

Gawande, Kishore and Usree Bandyopadhyay (2000). "Is protection for sale? Evidence on the Grossman-Helpman theory of endogenous protection." Review of Economics and Statistics, 82, pp. 139-152.

Glismann, Hans and Frank Weiss (1980). "On the political economy of protection in Germany.” World Bank Staff working paper \#427.

Goldberg Pinepoli, and Giovanni Maggi (1999). "Protection for sale: An empirical investigation." American Economic Review, 89, pp. 1135-1155.

Grossman, Gene and Elhanan Helpman (1994). "Protection for sale." American Economic Review, 84, pp. 833-850.

Grossman, Gene and Elhanan Helpman (1996). "Rent dissipation, free riding, and trade policy." European Economic Review, 40, pp. 795-803.

Hansen, John (1990). "Taxation and the political economy of the tariff," International Organisation, 44, pp. 527-552.

Hillman, Ariel (1989). The Political Economy of Protection, New York: Harwood Academic Publishers.

Hillman, Arye (1982). "Declining industries and political-support protectionists motives," American Economic Review, 72, pp 1180-1187.

Hufbauer, Gary, Diane Berliner and Kimberly Elliot (1986). Trade Protection in the United States: 31 Case Studies. Institute for International Economics, Washington, D.C.

Hufbauer, Gary and Howard Rosen (1986). Trade Policy for Troubled Industries. Policy Analyses in International Economics 15, Institute for International Economics Washington, D.C.

Krueger, Anne (1990). "Asymmetries in policy between exportables and import-competing goods." In The political economy of international trade, edited by Ronald Jones and Anne Krueger. Cambridge MA: Basil Blackwell.

Lavergne, Real (1983). The Political Economy of US Tariffs: An Empirical Analysis. Academic Press. 
Magee, Stephen P., William A. Brook and Leslie Young (1989). Black Holes Tariffs and Endogenous Policy Theory. Cambridge University Press.

Marceau, Nicholas and Michael Smart (2003). "Corporate lobbying and commitment failure in capital taxation." American Economic Review, 93, pp. 241-251.

Marvel, Howard and Edward Ray (1983). "The Kennedy Round: Evidence on the regulation of trade in the US." American Economic Review, 73, pp 190-197.

Matsuyama, Kiminori (1987). "Perfect equilibrium in a trade liberalisation game." American Economic Review 80, pp. 480-482.

Mitra, Devashish (1999). "Endogenous lobby formation and endogenous protection." American Economic Review, 89, pp. 1116-1134.

O’Halloran, Sharyn (1994). Politics, Process, and American Trade Policy. Ann Arbor: University of Michigan Press.

Olson, Mancur (1965). The logic of collective action. Cambridge MA: Harvard University Press.

Peltzman, Sam (1976). "Toward a more general theory of regulation." Journal of Law and Economics, 19, pp. 221-240.

Ray, Edward (1987). "Changing patterns of protectionism: The fall in tariffs and the rise in non-tariff barriers." Northwestern Journal of International Law and Business, 8, pp. 285-327.

Ray, Edward (1991). "Protection of manufactures in the US." in Global protectionism: Is the US playing on a level field? Edited by David Greenaway. London: Macmillan.

Rodrik, Dany (1995). "Political economy of trade policy" In Handbook of International Economics (vol. 3), edited by Gene Grossman and Keneth Rogoff. Amsterdam: Elsevier.

Rotemberg, Julio (2003). "Commercial policy with altruistic voters." Journal of Political Economy, 111(1), pp. 174-201.

Sauré, Philip (2005). "How to use subsidies to sustain trade agreements." Universitat Pompeu Fabra, Barcelona and European University Institute, Florence.

Schelling, Thomas (1984). Choices and consequence, Harvard University Press, Cambridge MA.

Stigler, George (1971). “The theory of economic regulation.” Bell Journal of Economic Management, 2, pp. 3-21.

Trefler, Daniel (1993). "Trade liberalisation and the theory of endogenous protection." Journal of Political Economy, 101, pp 138-160.

Van Long, N. and N. Vousden (1991). "Protectionist responses and declining industries." Journal of International Economics, 30, pp. 87-103. 


\section{CENTRE FOR ECONOMIC PERFORMANCE Recent Discussion Papers}

$790 \quad$ Alan Manning Sanchari Roy

789 Giorgio Gobbi Roberta Zizza

788 Nick Bloom Raffaella Sadun John Van Reenen

787 Elizabeth O. Ananat Guy Michaels

786 Willem H. Buiter

785 Gustavo Crespi Chiara Criscuolo Jonathan E. Haskel Matthew Slaughter

784 Richard Layard Guy Mayraz Stephen Nickell

783 Gustavo Crespi Chiara Criscuolo Jonathan E. Haskel

782 Paul Castillo Carlos Montoro Vicente Tuesta

781 David Metcalf

780 Carlos Montoro

779 Sharon Belenzon Mark Schankerman

778 Henry G. Overman Diego Puga Matthew A. Turner

777 Florence Kondylis

776 Willem H. Buiter
Culture Clash or Culture Club? The Identity and Attitudes of Immigrants in Britain

Does the Underground Economy Hold Back Financial Deepening? Evidence from the Italian Credit Market

Americans do I.T. better: US Multinationals and the Productivity Miracle

The Effect of Marital Breakup on the Income Distribution of Women with Children

Seigniorage

Productivity Growth, Knowledge Flows and Spillovers

The Marginal Utility of Income

Information Technology, Organisational Change and Productivity Growth: Evidence from UK Firms

Inflation Premium and Oil Price Volatility

Why Has the British National Minimum Wage Had Little or No Impact on Employment?

Monetary Policy Committees and Interest Rate Smoothing

Harnessing Success: Determinants of University Technology Licensing Performance

Decomposing the Growth in Residential Land in the United States

Conflict-Induced Displacement and Labour Market Outcomes: Evidence from Post-War Bosnia and Herzegovina

Is Numérairology the Future of Monetary Economics? Unbundling numéraire and medium of exchange through a virtual currency and a shadow exchange rate 
775 Francesco Caselli

Nicola Gennaioli

774 Paul Willman

Alex Bryson

773 Alan Manning

772 Guy Michaels

771 Gianluca Benigno

Christoph Thoenissen

770 Michael Smart

Daniel M. Sturm

769 Andrew B. Bernard

Stephen J. Redding

Peter K. Schott

768 Paul Willman

Alex Bryson

767 Anthony J. Venables

766 Guy Michaels

765 Fabrice Murtin

764 Carlo Rosa

Giovanni Verga

763 Benjamin AlemanCastilla

762 L. Rachel Ngai

Roberto M. Samaniego
Economics and Politics of Alternative Institutional Reforms

Union Organization in Great Britain

Prepared for symposium for the Journal of Labor

Research on "The State of Unions: A Global

Perspective"

The Plant Size-Effect: Agglomeration and

Monopsony in Labour Markets

The Effect of Trade on the Demand for Skill -

Evidence from the Interstate Highway System

Consumption and Real Exchange Rates with

Incomplete Markets and Non-Traded Goods

Term Limits and Electoral Accountability

Multi-Product Firms and Trade Liberalization

Accounting for Collective Action: Resource

Acquisition and Mobilization in British Unions

Shifts in Economic Geography and their Causes

The Long-Term Consequences of Regional Specialization

American Economic Development Since the Civil War or the Virtue of Education

The Impact of Central Bank Announcements on Asset Prices in Real Time: Testing the Efficiency of the Euribor Futures Market

The Effect of Trade Liberalization on Informality and Wages: Evidence from Mexico

An R\&D-Based Model of Multi-Sector Growth

The Centre for Economic Performance Publications Unit

Tel 02079557673 Fax 02079557595 Email info@cep.Ise.ac.uk

Web site http://cep.lse.ac.uk 